\title{
Synthesis and Characterization of Structural and Optical Properties of ZnO Nano-Particles
}

\author{
Madhuri Samel $^{1}$, Nileema Patil ${ }^{2}$, Priya Tilak ${ }^{3}$ \\ ${ }^{1}$ LokmanyaTilak College of Engineering, Navi Mumbai, Maharashtra, India-400709
}

\begin{abstract}
In the recent era zinc oxide nanoparticles proved promising field for researchers due to their unique properties and applications in optoelectronic devices. $(\mathrm{ZnO})$ is a distinctive electronic and photonic wurtzite n-type semiconductor with a wide direct band gap of $3.37 \mathrm{eV}$ and a high exciton binding energy $(60 \mathrm{meV})$ at room temperature.Zno nanoparticles were prepared using wet chemical method with varying binder concentration of starch. Sizes of overnight dried suspension were determined using several analytical techniques. Theoretical and analytical considerations were evaluated, results were compared which confirms the formation of nanosize.Synthesized nanoparticles were characterized by XRD, AFM,particle size analyzer and UV visible spectrumm.etc. XRD AFM confirmed the nanosized zinc oxide particles. $U V$-spectroscopy shows the transparency of nanoparticles over entire visible range.
\end{abstract}

Keywords: Nano particles, sonication method, diffractometer

\section{Introduction}

Zno nanoparticles have been famous among researchers as well promising candidate due to its various applications like gas sensors[1] bio sensors[2-3] solar cells[4] superconductors[5] varistors[6] photo detectors[7] photo catalyst[8], optoelectronic devices[9],cosmetics [10]etc. $\mathrm{ZnO}$ is distinctive electronic and photonic Wurtzite n-type semiconductor with a direct band gap of $3.37 \mathrm{eV}$ and a high exciton binding energy $(60 \mathrm{meV})$ at room temperature $[11,12]$. The high exciton binding energy of $\mathrm{ZnO}$ would allow for excitonictransitions even at room temperature, which could mean high radiative recombination efficiency for spontaneous emission as well as a lower threshold voltage for laser emission. The lack of a centre of symmetry in wurtzite, combined with a large electromechanical coupling, results in strong piezoelectric and pyroelectric properties and hence the use of $\mathrm{ZnO}$ in mechanical actuators and piezoelectric sensors $[13,14] \mathrm{ZnO}$ has high optical transparency and Luminescence in visible and near ultraviolet range of spectrum. Therefore, it is usually used in light emitting diodes and solar cells. $\mathrm{ZnO}$ nanoparticles are having high exciton binding energy nearly $60 \mathrm{meV}$. This means the excitonic transition in case of $\mathrm{ZnO}$ nanoparticles is possible at room temperature also [15-17]. Moreover many techniques are being used to synthesize $\mathrm{ZnO}$ nanoparticles Viz. precipitation method, spray pyrolysis method, micro emulsion method, hydro thermal method and Sol gel method. In the present investigation the sol-gel method for synthesis of $\mathrm{ZnO}$ nanoparticles was chosen as it is simplest method, consumes less power and can be carried out in robust atmosphere. Zinc Oxide is environmental friendly and ease to synthesize

\section{Experimental Method}

Zinc nitrate and sodium hydroxide are used as precursors. Starch has been used as stabilizing agent or binder. By using three different concentrations of stabilizing agent $(0.1 \%, .0 .5$ $\%, 1 \%$ ) three samples are prepared.

\section{Structural Properties}

During the present work $\mathrm{X}$ - ray diffraction pattern was recorded in $\theta-2 \theta$ scan mode by using a JEOL JDX $8030 \mathrm{X}$ ray diffractometer at University department of physics, Santacruz, Mumbai. The radiation source used was $\mathrm{Cu}-\mathrm{Ka}$ $(\lambda=1.54018 \AA$ ). We have scanned the angle in the range of 20 to 80 degree. The Powder software was used to obtain data of XRD.Nanoparticle shows peak broadening. This broadening is observed for particles with diameter size less than $100 \mathrm{~nm}$. In this case, particle size is measured by Debye Sherrer formula.

\section{Particle size $=0.9 \lambda / \mathrm{FWHM}(\operatorname{COS} \theta)$}

$\lambda$ - the wavelength of the incident X-Ray

$\theta$ - is the angle corresponding to the peak

FWHM- the full width at half maximum in radiance.

The comparison of the XRD s for the three samples is shown figure. It is seen that the peaks are obtained at same position but there is change in the intensities of respective peaks. The obtained peaks are comparable with the standard sample. Average Particle size $=19.46 \mathrm{~nm}$

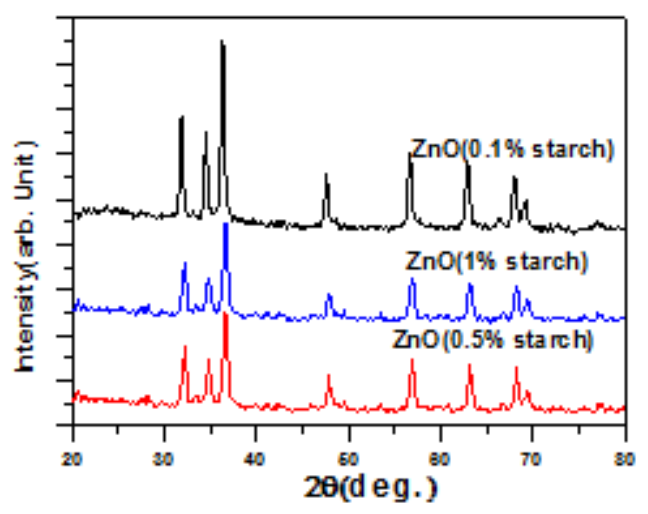

Figure 1: Comparisons of XRDS 


\section{International Journal of Science and Research (IJSR) \\ ISSN (Online): 2319-7064}

Index Copernicus Value (2013): 6.14 | Impact Factor (2015): 6.391

\section{Comparison of Concentration with Particle Size}

Table 1: Comparison of concentration with Particle Size

\begin{tabular}{|c|c|}
\hline Binder (conc.) & Particle Size(nm) \\
\hline $0.10 \%$ & 19.46 \\
\hline $0.50 \%$ & 18.34 \\
\hline $1 \%$ & 17.08 \\
\hline
\end{tabular}

For preparation of sample 1 we used $0.1 \%$ of starch as a binder in which we found average particle size as $19.46 \mathrm{~nm}$. The $0.5 \%$ sample has average size of $18.34 \mathrm{~nm}$ and for $1 \%$ of starch sample average particle size reduced to $17.08 \mathrm{~nm}$. It is seen from the above data that as the binder concentration increases the particle size goes on reducing.The experiment is carried out at room temperature.

Particle size $=0.9 \lambda /$ FWHM COS $\theta$

Average Particle size $=19.46 \mathrm{~nm}$

\section{Morphological Study}

The AFM imaging is carried out by using AFM machine by Vecco.The powder sample is sonicated in Distilled water. A drop of the dispersion is put on the glass. The surface is scanned by using the contact mode, which protects the surface damage. The 3D images of samples are given above. It is seen that particle are not separate out but agglomeration is observed. We tried different techniques of sample preparation for imaging purpose but could not get the wellseparated particles. The particle size varies from 30 to 100 $\mathrm{nm}$. There may be cluster formation.

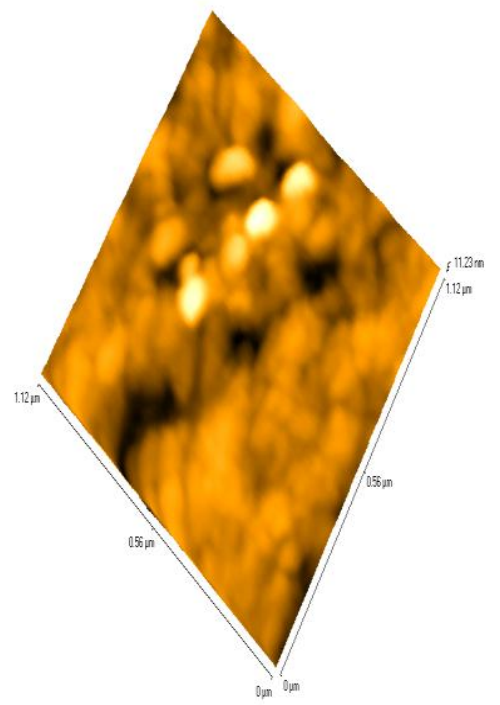

Figure 2: 3D AFM image of sample

\section{Optical Properties}

The UV spectra obtained by using SHIMADZU UV- 2401 machine at university department of chemistry for the various samples in shown below. The incident in wavelength is in the range of $300-800 \mathrm{~nm}$. The sample will be absorbing wavelength depending on its concentration. The sample was prepared by sonication method. The small quantity of the powder sample was added to the distilled water. This solution was sonicated to get dispersion of the sample. Then this dispersion was pour in the reference cell for UV Absorption The size of the nanoparticles is crucial factor to determine properties of materials. Thus, size evolution of semiconductingnanoparticles becomes very essential to explore the properties of the materials. UVvisible absorption spectroscopyis widely being used technique to examine the optical properties of nanosized particles. The absorption spectrum of $\mathrm{Zn} 0$ nanopowder is shown in Figure. It exhibits astrong absorption band at about $355 \mathrm{~nm}$ an excitonic measurement.

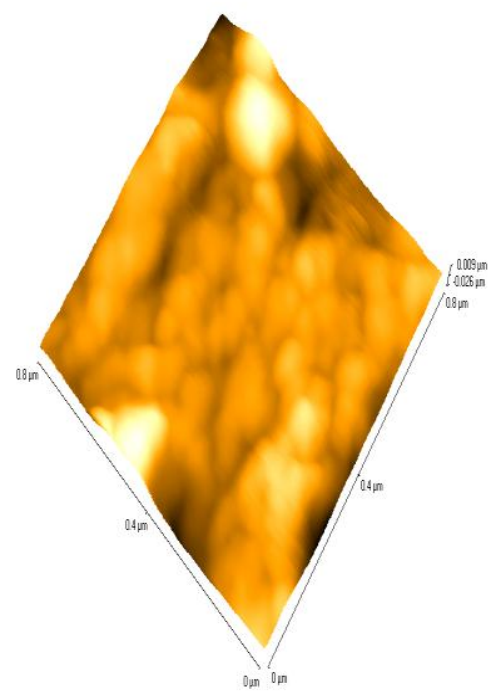

Figure 3:3D image of Sample

Band Gap is calculated by using following formula$\mathrm{Eg}=\mathrm{hc} / \lambda$

For sample $1(0.1 \%$ starch $)$

$\lambda=360 \mathrm{~nm}$

$\mathrm{Eg}=3.47 \mathrm{ev}$

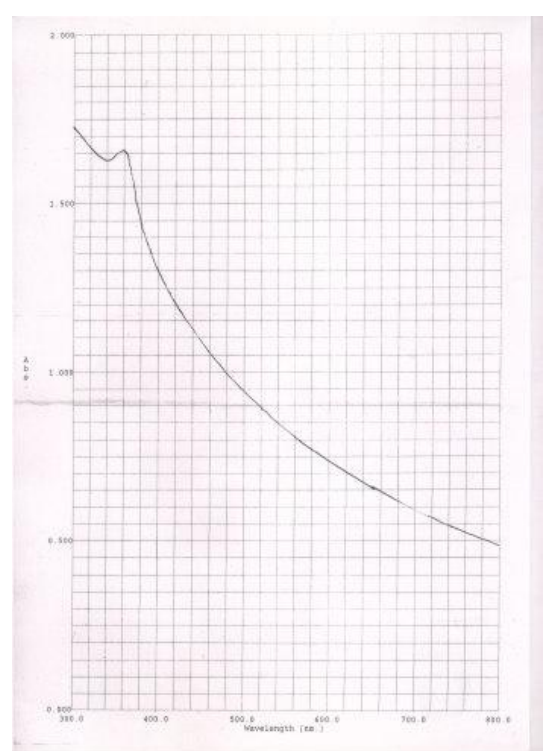

Figure 4: Absorption Spectra

Table 2: Analysis of variation in Band Gap

\begin{tabular}{|c|c|c|c|}
\hline $\begin{array}{c}\text { Binder } \\
\text { concentration }\end{array}$ & $\begin{array}{c}\text { Absorption } \\
\text { coefficient }\end{array}$ & $\begin{array}{c}\text { Exition } \\
\text { Wavelength(nm) }\end{array}$ & $\begin{array}{c}\text { Band } \\
\text { Gap(ev) }\end{array}$ \\
\hline 0.1 & 1.663 & 360 & 3.47 \\
\hline 0.5 & 1.729 & 360.5 & 3.46 \\
\hline 1 & 0.54 & 372.5 & 3.35 \\
\hline
\end{tabular}

Volume 5 Issue 6, June 2016 www.ijsr.net 


\section{International Journal of Science and Research (IJSR) ISSN (Online): 2319-7064}

Index Copernicus Value (2013): 6.14 | Impact Factor (2015): 6.391

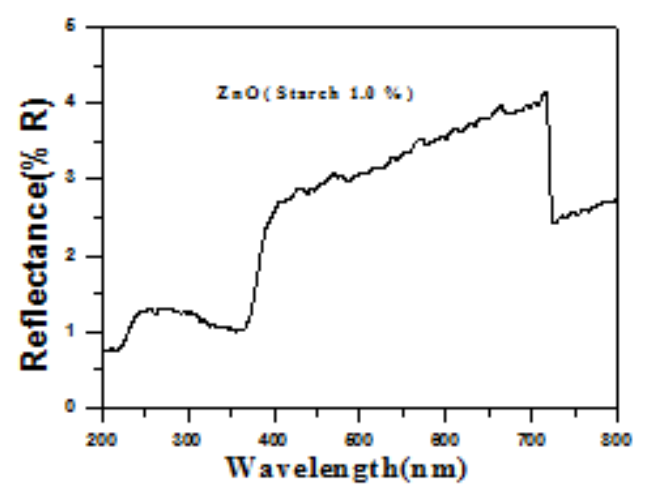

Figure 4: Relationship of Reflectance with Wavelength

Using Following equations

$3.8 \mathrm{R}^{2}=(\mathrm{n}-1) /(\mathrm{n}+1)$

R- Reflectance coefficient.

$\mathrm{n}$ - Refractive Index

From the reflectance spectra of the Zno at wavelength 250 the coefficient is $1.2 \%$ i.e

$\mathrm{R}=0.12$

Substituting in the above equation it gives

$\mathrm{n}=1.0292$

The optical density is given by

$\ln (1-\mathrm{R})^{2} / \mathrm{T}$

Optical density $=0.275$

\section{Results and Discussion}

$\mathrm{ZnO}$ nanoparticles have been prepared using wet chemicalsynthesis method and were characterized by $\mathrm{XRD}, \mathrm{AFM}$,UV-vis absorption,. XRD and AFM studies confirmed the nanostructures for the prepared $\mathrm{ZnO}$ nanoparticles.The Absorption spectra gives the band gap value.Theexicitonic wavelength goes on increasing as the binder concentration increases. The value of Band gap goes on decreasing as per increasing binder concentration. The reflectance spectra show that at the exicitonic peak in absorption spectra dip is observed in the Reflectance spectra. The prepared $\mathrm{ZnO}$ nanoparticles exhibit $(\lambda$ exc $=360 \mathrm{~nm})$ sharp UV bandcorresponding to near band gap excitonic emission at room temperature. These $\mathrm{ZnO}$ nanoparticles can be used indifferent industrial applications, namely, luminescent material for fluorescent tubes, active medium for lasers, sensors, and so forth.

\section{References}

[1] X. L. Cheng, H. Zhao, L. H. Huo, S. Gao, and J. G. Zhao, "ZnO nanoparticulate thin film: preparation, characterization andgas-sensingproperty," Sensors and Actuators, B, vol. 102, no.2, pp. 248-252, 2004.

[2] Z. L. Wang, "Nanostructures of zinc oxide," Materials Today,vol. 7, no. 6, pp. 26-33, 2004.

[3] C. N. R. Rao and A. Govindaraj, in Nanotubes and Nanowires,H. Kroto, P. O'Brien, and H. Craighead, Eds., The RSC Nano-science and Nanotechnology Series, Royal Society ofChemistry, London, UK, 2005

[4] Y. Hames, Z. Alpaslan, A. K̈̈osemen, S. E. San, andY. Yerli,"Electrochemically grown ZnOnanorods for hybrid solar cellapplications," Solar Energy, vol. 84, no. 3, pp. 426-431, 2010 .
[5] Parmanand Sharma, Amita Gupta, K.V. Rao, Frank J. Owens, Renu Sharma, Rajeev Ahuja,J.M. Osorio Guillen, BörjeJohansson and Gehring, Ferromagnetism above roomtemperature in bulk and transparent thin films of Mn-doped ZnO,nature materials, 2, 673(2003).

[6] W. Jun, X. Changsheng, B. Zikui, Z. Bailin, H. Kaijin, and W.Run, "Preparation of $\mathrm{ZnO}$-glass varistor from tetrapod ZnOnanopowders," Materials Science and Engineering B, vol. 95,no. 2, pp. 157-161, 2002.

[7] P. Sharma, K. Sreenivas, and K. V. Rao, "Analysis of ultraviolet photoconductivity in $\mathrm{ZnO}$ films prepared by unbalanced mag-netron sputtering," Journal of Applied Physics, vol. 93, no. 7, pp.3963-3970, 2003.

[8] P. V. Kamat, R. Huehn, and R. Nicolaescu, "A "sense and shoot" approach for photocatalytic degradation of organiccontaminants in water,"

[9] Shuyan Shao, KaiboZheng, KarelZidek, PavelChabera, TonuPullerits and FenglingZhang,OptimizingZnO nanoparticle surface for bulk heterojunction hybrid solar cells, SolarEnergy Materials and Solar Cells, 118, 43 (2013).

[10] S. VenkataprasadBhat, A. Govindaraj, C. N. R. Rao, Hybrid solar cell based on P3HT-ZnOnanoparticle blend in the inverted device configuration, Solar Energy Materials \& SolarCells, 95, 2318 (2011).

[11] [10] Yunfei Zhou, Michael Eck and Michael Krüger, Organic-Inorganic Hybrid Solar Cells:Stateof the Art, Challenges and Perspectives, Solar Cells - New Aspects and Solutions, 95(2011).

[12] Mohammad Vaseem, Ahmad Umar, Yoon-Bong Hahn, Metal Oxide Nanostructures andTheir Applications, American Scientific Publishers (2010) ch4,Pp 1-36.

[13] S. C. Ko, Y. C. Kim, S. S. Lee, S. H. Choi, and S. R. Kim"Micromachined piezoelectric membrane acoustic device,"Sensors and Actuators, A, vol. 103, no. 1-2, pp. 130-134, 2003.Journal of Physical Chemistry B, vol.106, no. 4, pp. 788-794, 2002.

[14] D. Zaouk, Y. Zaatar, R. Asmar, and J. Jabbour, "Piezoelectriczinc oxide by electrostatic spray pyrolysis," MicroelectronicsJournal, vol. 37, no. 11, pp. 1276-1279, 2006.

[15] Soosen Samuel M, Lekshmi Bose and George KC, Optical properties of ZnOnanoparticles,SB Academic Review, 16(1 \& 2), 57 (2009).

[16] Peng W Q, Qu S C, Cong G W and Wang Z G, Structure and visible luminescence of ZnOnanoparticles, Mater. Sci. Semic. Proc., 9,156 (2006).

[17] Yu Q, Fu W, Yu C, Yang H, Wei R, Sui Y, Lui Y, Lui Z, Li M, Wang G, Shao C, Lui Y andZou G, Structural Electrical and Optical properties of Yttrium doped $\mathrm{ZnO}$ nanoparticles, J.Phys. D:)

\section{Author Profile}

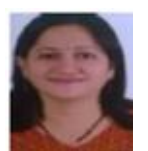

Mrs. Madhuri Samel is having M.Phil. and M.Sc. degree in Physics. Currently she is working as Assistant Professor in Applied Physics department at LokmanyaTilak College of Engineering; Navi Mumbai .She is having total teaching experience of 8 years 


\section{International Journal of Science and Research (IJSR) \\ ISSN (Online): 2319-7064}

Index Copernicus Value (2013): 6.14 | Impact Factor (2015): 6.391

Mrs Nileema Patil is having M.Sc. degree in Physics.

Currently she is working as Assistant Professor in

Applied Physics department at LokmanyaTilak

College of Engineering; Navi Mumbai .She is having

total teaching experience of 12 Years

Mrs PriyaTilak is having M.Sc. degree in Physics. Currently she is working as Assistant Professor in Applied Physics department at LokmanyaTilak College of Engineering; Navi Mumbai .She is having total teaching experience of 19 years

Volume 5 Issue 6, June 2016 www.ijsr.net 